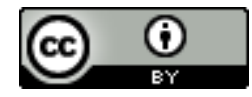

Esta obra está sob o direito de Licença Creative Commons Atribuição 4.0 Internacional.

\title{
REUSO DE ÁGUA COMO FERRAMENTAS DE GESTÃO DE RECURSOS HÍDRICOS
}

\author{
Gabryell Henrique Amancio da Silva \\ José Carlos Firmino da Silva ${ }^{2}$ \\ Joseval José de Souza Filho ${ }^{3}$ \\ Manoel Luiz Guimarães Neto ${ }^{4}$ \\ Vinícius Carvalho de Santana 5 \\ Eduardo Cabral da Silva ${ }^{6}$
}

\begin{abstract}
RESUMO
Atualmente as populações, principalmente as urbanas, enfrentam problemas relacionados à escassez de água potável em qualidade e quantidade, devido à irregularidade das chuvas principal responsável pelo abastecimento das bacias hidrográficas - e também devido a deficiência na gestão dos recursos hídricos. O presente artigo tem como objetivo apresentar trabalhos que abordem as estratégias viáveis do ponto de vista econômico e ambiental para o desenvolvimento de projetos de reuso, buscando abordar as temáticas do gerenciamento e da redução da carga de efluentes na rede de esgoto. Para produção do trabalho foram pesquisados artigos científicos publicados nos últimos cinco anos, através de pesquisa no Periódico Capes, por meio de uma revisão sistemática integrativa, a partir da seguinte pergunta norteadora: quais as vantagens socioeconômicas e ambientais que o reuso de águas pode gerar? De posse do material pesquisado, concluiu-se que os sistemas de reuso se constituem como ferramenta de gestão de recursos hídricos, pois reduzem a demanda de água dos mananciais, assim como, minimizam o escoamento de efluentes na rede de esgoto.
\end{abstract}

Palavras-chave: Recursos hídricos. Reuso. Gestão.

\footnotetext{
${ }^{1}$ henriquegabryell08@hotmail.com

2 carlosbgstudio@gmail.com

3 eng.josevalfilho@ hotmail.com

${ }^{4}$ manoelluizneto@gmail.com

${ }^{5}$ vinnycihus2011@hotmail.com

${ }^{6}$ eduardo.csilva@professores.unifavip.edu.br
} 


\section{INTRODUÇÃO}

O acesso aos recursos hídricos é um direito de todos e com isso tem-se como principal objetivo atender todas as necessidades humanas. A partir disso faz-se importante ter uma gestão de recursos hídricos capaz de suprir essas necessidades de forma racional, ou seja, de maneira viável economicamente e respeitando sempre os limites ambientais sem que haja desperdícios desses recursos.

Portanto, o reuso dos recursos hídricos deve se tornar cada vez mais rotineiro na vida de todos, seja tanto por parte da população reaproveitando-a de forma plausível nas tarefas domésticas quanto das companhias que devem fazer a distribuição para a população de maneira sustentável e que atenda todos os padrões de qualidade e quantidade.

É fato que a água pluvial é a principal fonte de abastecimento das bacias hidrográficas e com isso, a captação e o direcionamento dessa água precisam ser de forma consciente, eficaz e bem planejada. Sendo assim, é imprescindível a participação pública na elaboração de projetos de infraestrutura que atendam as condições impostas pelo clima da região e aos critérios estabelecidos por normas.

Desde já, todo caminho que a água pluvial percorre até chegar no reservatório deve ser bem projetado e protegido para que não haja contato da mesma com os efluentes, portanto, é de fundamental importância a participação de entidades como ANA (Agência Nacional de Águas) no comportamento e elaboração de projetos e diretrizes para que haja um maior aproveitamento possível desses recursos hídricos.
Portanto, o presente estudo tem como objetivo apresentar artigos científicos atualizados sobre as principais estratégias que busquem viabilidade econômica e ambiental do reuso de águas.

O estudo se justifica pela relevância da temática para a gestão dos recursos hídricos e para mitigação do lançamento de efluentes na rede de drenagem.

\section{MÉTODOLOGIA}

Trata-se de uma revisão bibliográfica do tipo sistemática integrativa, que seguiu as seguintes etapas (ver Quadro 1): $1^{a}$ ) Definição do tema, seleção da pergunta norteadora e escolha da estratégia de busca, descritores e bases de dados mais eficazes no levantamento das publicações; $2^{\text {a }) ~ E s c o l h a ~ d o s ~ c r i t e ́ r i o s ~ d e ~ i n c l u s a ̃ o ~ e ~}$ exclusão; $3^{\text {a }}$ ) Identificação dos estudos préselecionados e selecionados através da leitura dos agentes indexadores das publicações, como resumo, palavras-chave e título, bem como organização dos estudos pré-selecionados e identificação dos estudos selecionados; $4^{\mathrm{a}}$ ): Categorização dos estudos selecionados, com elaboração e uso da matriz de síntese, além de análise das informações, formação de uma biblioteca individual e avaliação crítica dos estudos selecionados; $5^{\text {a }}$ ) análise, interpretação e discussão dos resultados; $6^{\mathbf{a}}$ ) Apresentação da revisão em formato de artigo, o qual contemple propostas para estudos futuros (BOTELHO; CUNHA; MACEDO, 2011; SCHMOELLER et al., 2011). Os quadros a seguir detalham as etapas da revisão abrangente do sistema e os resultados obtidos 


\section{QUADRO 1 \\ DETALHAMENTO DAS ETAPAS DA REVISÃO SISTEMÁTICA INTEGRATIVA.}

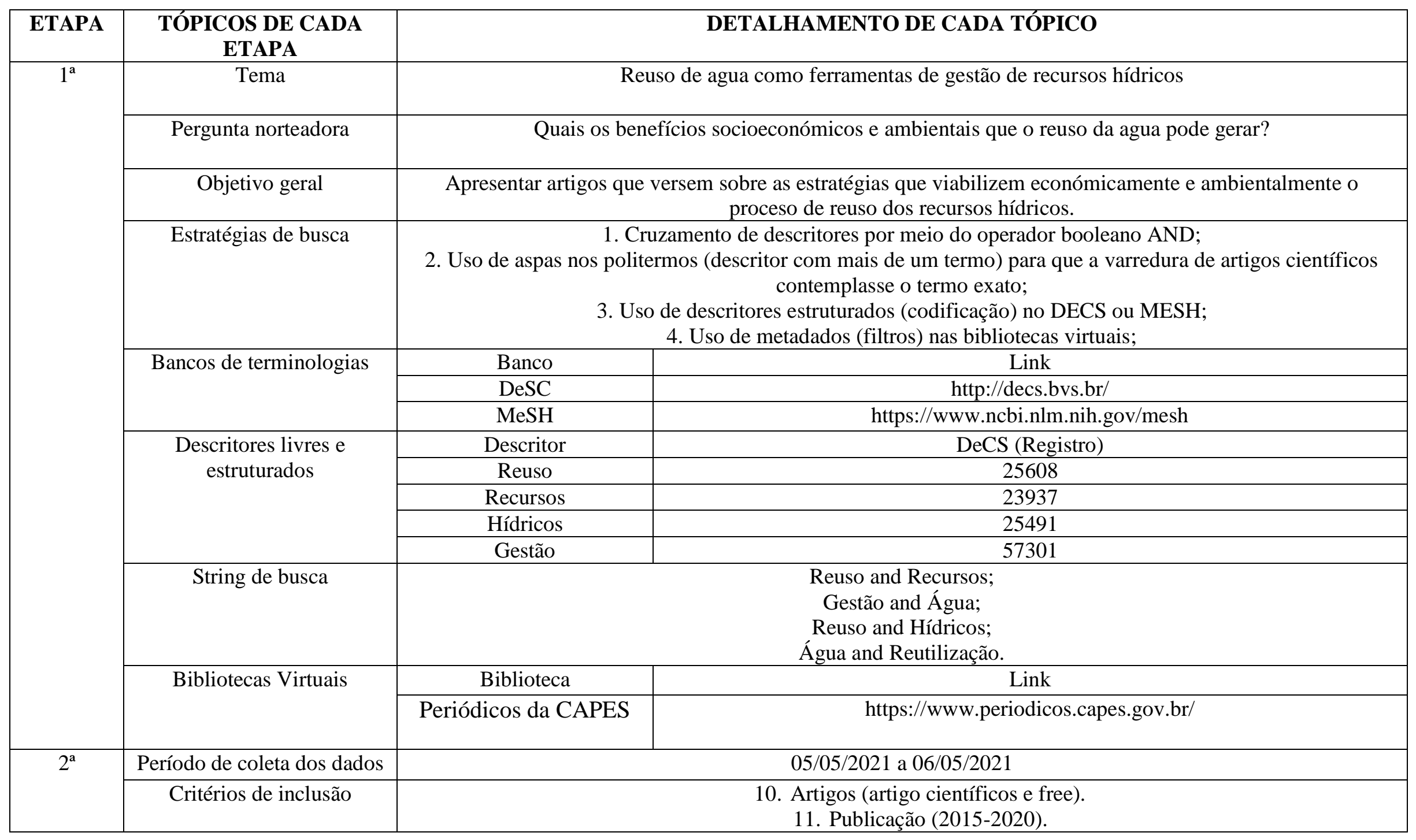




\begin{tabular}{|c|c|c|}
\hline & Critérios de exclusão & 4. Artigos que não contemplam a temática \\
\hline $3^{\mathrm{a}}$ & $\begin{array}{c}\text { Número de trabalhos } \\
\text { selecionados para revisão } \\
\text { sistemática integrativa a } \\
\text { partir da leitura dos agentes } \\
\text { indexadores das publicações } \\
\text { (tema, descrição, ementa). }\end{array}$ & 10 \\
\hline $4^{a}$ & $\begin{array}{l}\text { Categorias obtidas com a } \\
\text { análise dos documentos } \\
\text { investigados online } \\
\text { gratuitos e de livre acesso }\end{array}$ & 2 \\
\hline $5^{\mathrm{a}}$ & $\begin{array}{l}\text { Análise, interpretação e } \\
\text { discussão dos resultados }\end{array}$ & Ver em "Resultados e Discussão" \\
\hline $6^{\mathrm{a}}$ & $\begin{array}{c}\text { Apresentação da revisão em } \\
\text { formato de artigo, o qual } \\
\text { contemple propostas para } \\
\text { estudos futuros }\end{array}$ & Este Artigo completo \\
\hline
\end{tabular}

Fonte: elaborada pelos autores 


\section{RESULTADOS}

O Quadro 2 detalha o quantitativo das pesquisas realizadas na biblioteca do Periódico Capes com as diferentes strings.
A string "água And reutilização" foi a que resultou num maior número de artigos selecionados para a discussão do presente trabalho (5 artigos).

Quadro 2

Total de documentos disponíveis no Periódicos CAPES obtidos por meio das strings de busca.

\begin{tabular}{|c|c|c|c|c|}
\hline String de busca & $\begin{array}{c}\text { Bases de } \\
\text { dados }\end{array}$ & $\begin{array}{c}\text { Total de } \\
\text { publicações } \\
\text { sem o filtro }\end{array}$ & $\begin{array}{c}\text { Publicações } \\
\text { disponíveis } \\
\text { após aplicar os } \\
\text { filtros } \\
\end{array}$ & $\begin{array}{c}\text { Publicações } \\
\text { aproveitadas na } \\
\text { Revisão Sistemática } \\
\text { Integrativa }\end{array}$ \\
\hline $\begin{array}{l}\text { Reuso And } \\
\text { Recurso }\end{array}$ & $\begin{array}{l}\text { Periódico } \\
\text { CAPES }\end{array}$ & 296 & 136 & 2 \\
\hline Gestão And Água & $\begin{array}{l}\text { Periódico } \\
\text { CAPES }\end{array}$ & 5.665 & 2.454 & 2 \\
\hline $\begin{array}{c}\text { Reuso And } \\
\text { Hídricos }\end{array}$ & $\begin{array}{l}\text { Periódico } \\
\text { CAPES }\end{array}$ & 253 & 120 & 1 \\
\hline $\begin{array}{c}\text { Água And } \\
\text { Reutilização }\end{array}$ & $\begin{array}{l}\text { Periódico } \\
\text { CAPES }\end{array}$ & 505 & 215 & 5 \\
\hline
\end{tabular}

Fonte: elaborada pelos autores.

O Quadro 3 apresenta a descrição dos dez artigos selecionados para discussão. Nele podem ser visualizados a autoria dos artigos, o título, o link de publicação, a data de publicação e a conclusão, a qual deu suporte para criação da nuvem de palavras (Figura 1). 
QUADRO 3

DESCRIÇÃO DOS DOCUMENTOS (ARTIGOS) DE ACORDO COM OS CRITÉRIOS DE INCLUSÃO.

\begin{tabular}{|c|c|c|c|c|c|}
\hline $\mathbf{N}^{\mathbf{o}}$ & Autor(a) & Tema & $\begin{array}{c}\text { Link da } \\
\text { publicação }\end{array}$ & $\begin{array}{c}\text { Data de } \\
\text { publicação }\end{array}$ & Conclusão \\
\hline 1 & $\begin{array}{c}\text { Vanessa Silva } \\
\text { Chaves; } \\
\text { Tatiana } \\
\text { Máximo } \\
\text { Almeida } \\
\text { Albuquerque; } \\
\text { Luciana } \\
\text { Coêlho } \\
\text { Mendonça. }\end{array}$ & $\begin{array}{c}\text { Análise da } \\
\text { viabilidade } \\
\text { econômica, } \\
\text { ambiental e social } \\
\text { da implantação do } \\
\text { sistema de reuso de } \\
\text { água em uma } \\
\text { indústria de } \\
\text { revestimento } \\
\text { cerâmico }\end{array}$ & $\begin{array}{l}\text { http://revistad } \\
\text { ae.com.br/arti } \\
\text { gos/artigo_ed } \\
\text { icao_228_n_- } \\
\text { 1940.pdf }\end{array}$ & $01 / 12 / 2020$ & $\begin{array}{l}\text { Diante dos resultados obtidos, verificou-se que, quanto ao aspecto } \\
\text { econômico, a implementação dessa técnica requer um alto } \\
\text { investimento inicial e, para a empresa analisada, não traz retorno } \\
\text { financeiro, já que esta não paga pela água captada por meio dos poços, } \\
\text { que é utilizada em todo o processo produtivo. Porém, na ocasião da } \\
\text { efetivação da cobrança, considerando o alto consumo de água na etapa } \\
\text { de granulação e em toda a indústria, poderia trazer retorno em pouco } \\
\text { tempo. Considerando, por exemplo, que essa água fosse proveniente da } \\
\text { Compainha de Saneamento de Sergipe, a implantação do sistema de } \\
\text { reúso de água implicaria em uma economia de } \mathrm{R} \$ 12.237,12 \text { mensais e } \\
\text { o prazo para o retorno do investimento seria de, aproximadamente, } 1 \\
\text { ano e } 10 \text { meses. [...] }\end{array}$ \\
\hline 2 & $\begin{array}{l}\text { A.M.A. } \\
\text { Barbosa; J.L. } \\
\text { Tavares; J.A. } \\
\text { Navoni. }\end{array}$ & $\begin{array}{c}\text { Caracterização e } \\
\text { análise do potencial } \\
\text { da água produzida } \\
\text { como alternativa } \\
\text { para reuso }\end{array}$ & $\begin{array}{c}\text { http://www2.i } \\
\text { frn.edu.br/ojs } \\
\text { /index.php/H } \\
\text { OLOS/article } \\
\text { /view/9200/p } \\
\text { df }\end{array}$ & $11 / 12 / 2019$ & $\begin{array}{l}\text { A escassez hídrica é uma problemática que atinge várias regiões no } \\
\text { mundo, em particular as zonas semiáridas. A água de reúso é uma } \\
\text { alternativa plausível e eficiente para mitigar ao menos em parte este } \\
\text { problema. Os grandes volumes de água gerados na atividade } \\
\text { extrativista de petróleo podem ser convertidos de uma problemática a } \\
\text { uma alternativa de suplementação hídrica. Neste estudo, uma } \\
\text { caracterização físico-química da água produzida foi realizada de forma } \\
\text { a avaliar a adequação ou não adequação as normas vigentes. No } \\
\text { entanto, a sua utilização como recurso hídrico alternativo após } \\
\text { tratamento é aceitável. Estudos dirigidos que busquem avaliar a } \\
\text { sustentabilidade da implementação de tecnologias quanto à avaliação } \\
\text { da eficiência da dessalinização e a remoção de compostos orgânicos } \\
\text { persistentes serão necessários de se avaliar em estudos futuros. }\end{array}$ \\
\hline 3 & $\begin{array}{c}\text { Tadeus Dias } \\
\text { Duca; Junívio }\end{array}$ & $\begin{array}{l}\text { Gestão e } \\
\text { indicadores de } \\
\text { abastecimento de }\end{array}$ & $\begin{array}{l}\text { https://period } \\
\text { icos2.uesb.br/ } \\
\text { index.php/ge }\end{array}$ & $01 / 12 / 2017$ & $\begin{array}{l}\text { O gerenciamento de recursos hídricos para o abastecimento urbano é } \\
\text { relevante para as sociedades atuais, principalmente para os territórios } \\
\text { que apresentam características físico-geográficas de escassez periódica, }\end{array}$ \\
\hline
\end{tabular}




\begin{tabular}{|c|c|c|c|c|c|}
\hline & $\begin{array}{c}\text { da Silva } \\
\text { Pimentel. }\end{array}$ & $\begin{array}{l}\text { água no setor } \\
\text { urbano de Lagoa } \\
\text { Real-Bahia }\end{array}$ & $\begin{array}{c}\text { o/article/view } \\
\text { /2046/1947 }\end{array}$ & & $\begin{array}{c}\text { mal-uso e poluição. A análise referente a importância política dos } \\
\text { princípios voltados a gestão hídrica e/ou abastecimento urbano é } \\
\text { entendida de modo a compor a base de qualquer ação frente a uma } \\
\text { realidade, dessa forma, o seu entendimento e maior utilização prática } \\
\text { compõe-se como algo válido. [...] }\end{array}$ \\
\hline 4 & $\begin{array}{l}\text { Márcia } \\
\text { Araújo de } \\
\text { Almeida; } \\
\text { Wilson Fadlo } \\
\text { Curi. }\end{array}$ & $\begin{array}{l}\text { Gestão do uso de } \\
\text { água na bacia do } \\
\text { Rio Paraíba, PB, } \\
\text { Brasil com base em } \\
\text { modelos de outorga } \\
\quad \text { e cobrança }\end{array}$ & $\begin{array}{l}\text { https://www.s } \\
\text { cielo.br/j/amb } \\
\text { iagua/a/jHfG } \\
\text { hMv6SSt654 } \\
\text { FNNkgTtWd } \\
\text { /?format=htm } \\
\quad 1\end{array}$ & $12 / 09 / 2016$ & $\begin{array}{l}\text { O modelo de outorga utilizado no desenvolvimento da pesquisa } \\
\text { mostrou-se adequado para a finalidade de se garantir as outorgas } \\
\text { concedidas segundo uma ordem de prioridade de atendimento, bem } \\
\text { como avaliar a possibilidade de inserir novos pedidos para a sub bacia } \\
\text { controlada pelo reservatório em estudo. O modelo de cobrança } \\
\text { proposto, incorporando vários perfis de usuários de água por meio de } \\
\text { coeficientes variados, possibilita que a cobrança não tenha apenas uma } \\
\text { finalidade arrecadatória, mas que exerça seu papel de incentivo ao uso } \\
\text { racional, redução de perdas nos sistemas de abastecimento, melhorias } \\
\text { no tratamento de efluentes, e desestimule as reservas de água, pois } \\
\text { estas inviabilizam a entrada de novos usuários na bacia. [...] }\end{array}$ \\
\hline 5 & $\begin{array}{l}\text { Naassom } \\
\text { Wagner Sales } \\
\text { Morais; } \\
\text { André } \\
\text { Bezerra dos } \\
\text { Santos. }\end{array}$ & $\begin{array}{l}\text { Análise dos } \\
\text { padrões de } \\
\text { lançamento de } \\
\text { efluentes em } \\
\text { corpos hídricos e } \\
\text { de reuso de águas } \\
\text { residuárias de } \\
\text { diversos estados do } \\
\text { Brasil }\end{array}$ & $\begin{array}{l}\text { http://revistad } \\
\text { ae.com.br/arti } \\
\text { gos/artigo_ed } \\
\text { icao_215_n_- } \\
\text { 1764.pdf }\end{array}$ & $01 / 01 / 2019$ & $\begin{array}{l}\text { Por meio da análise dos padrões de lançamento de efluentes, percebeu- } \\
\text { se a diversidade na forma de abordagem dos limites, seja em termos de } \\
\text { concentração ou carga poluidora, não se observando uma } \\
\text { uniformização na adoção dos padrões de lançamento. Por meio do } \\
\text { estabelecimento dos níveis de restrição, constatou-se que alguns } \\
\text { estados mantêm uma postura muito restritiva, dificultando o } \\
\text { cumprimento da legislação devido ao alto nível de tratamento } \\
\text { requerido para alcançar determinado padrão. [...] }\end{array}$ \\
\hline 6 & $\begin{array}{l}\text { Renata } \\
\text { Cristina } \\
\text { Mendonça; } \\
\text { Khristyan } \\
\text { Lenner de } \\
\text { Andrade } \\
\text { Soares; }\end{array}$ & $\begin{array}{l}\text { Análise da } \\
\text { disponibilidade e } \\
\text { demanda de água } \\
\text { cinza no pavilhão } \\
\text { de aulas da } \\
\text { Universidade } \\
\text { Federal de Viçosa, }\end{array}$ & $\begin{array}{l}\text { http://www.u } \\
\text { cs.br/etc/revis } \\
\text { tas/index.php } \\
\text { /scientiacumi } \\
\text { ndustria/articl } \\
\text { e/view/4497/ } \\
\quad \text { pdf }\end{array}$ & $01 / 10 / 2016$ & $\begin{array}{l}\text { A falta de abastecimento de água, devido ao mau uso, vem } \\
\text { preocupando a sociedade. Assim, surgem as políticas de } \\
\text { conscientização, produtos são desenvolvidos e tecnologias são } \\
\text { estudadas, tudo para evitar este cenário. A água cinza é uma fonte } \\
\text { alternativa para os períodos em que houver escassez ou aumento do } \\
\text { preço do insumo. Entretanto, deve-se atentar para os cuidados a tomar } \\
\text { no reuso de tais águas, como a sua qualidade, a fim de evitar qualquer }\end{array}$ \\
\hline
\end{tabular}




\begin{tabular}{|c|c|c|c|c|c|}
\hline & $\begin{array}{l}\text { Lineker Max } \\
\text { Goulart } \\
\text { Coelho. } \\
\end{array}$ & $\begin{array}{l}\text { Campus Rio } \\
\text { Paranaíba-MG }\end{array}$ & & & $\begin{array}{c}\text { tipo de contaminação. Inclusive, todos os pontos em que essa água é } \\
\text { ofertada devem ser sinalizados. [...] }\end{array}$ \\
\hline 7 & $\begin{array}{c}\text { Elsbeth Léia } \\
\text { Spode } \\
\text { Becker; } \\
\text { Jussane } \\
\text { Rossato; } \\
\text { Anderson } \\
\text { Ellwanger. }\end{array}$ & $\begin{array}{l}\text { A preservação da } \\
\text { água em um objeto } \\
\text { de aprendizagem: } \\
\text { saberes e } \\
\text { possibilidades de } \\
\text { ensino }\end{array}$ & $\begin{array}{c}\text { http://www.s } \\
\text { eer.ufu.br/ind } \\
\text { ex.php/emrev } \\
\text { ista/article/vi } \\
\text { ew/49335/26 } \\
283\end{array}$ & $01 / 06 / 2019$ & $\begin{array}{c}\text { A partir do exposto, conclui-se que a composição multimodal, aula } \\
\text { expositiva, som, texto e AO mostraram-se eficazes para abordar o tema } \\
\text { água e, especialmente, induzir a reflexão para a preservação desse } \\
\text { recurso natural. [...] }\end{array}$ \\
\hline 8 & $\begin{array}{l}\text { L.G. } \\
\text { Pinheiro; } \\
\text { A.L.C. } \\
\text { Araújo. }\end{array}$ & $\begin{array}{l}\text { Qualidade e } \\
\text { aproveitamento da } \\
\text { água da chuva }\end{array}$ & $\begin{array}{c}\text { http://www2.i } \\
\text { frn.edu.br/ojs } \\
\text { /index.php/H } \\
\text { OLOS/article } \\
\text { /view/3431/p } \\
\text { df }\end{array}$ & $13 / 12 / 2016$ & $\begin{array}{l}\text { Dessa forma, a partir da avaliação da qualidade da água de chuva, } \\
\text { observa-se que a mesma apresenta grande potencial em ser utilizada } \\
\text { para fins não potáveis no Campus Central do IFRN, bem como em } \\
\text { outras localidades que apresentem altas taxas de pluviosidade. O } \\
\text { aproveitamento desse recurso oferece benefícios de cunho econômico, } \\
\text { social e ambiental, uma vez que promove o reuso de águas que seriam } \\
\text { descartadas no ambiente, promovendo redução no que diz respeito às } \\
\text { tarifas empregadas em contas de água, além de poder ser armazenada e } \\
\text { utilizada por populações que sofrem com irregularidade de chuvas e } \\
\text { escassez hídrica e proporcionar redução no consumo PINHEIRO \& } \\
\text { ARAÚJO (2016) HOLOS, Ano 32, Vol. } 08145 \text { de água potável, } \\
\text { valioso recurso ambiental que deve ser preservado.[...] }\end{array}$ \\
\hline 9 & $\begin{array}{l}\text { D.M. Torres; } \\
\text { S.S. } \\
\text { Nascimento; } \\
\text { J.F. Souza; } \\
\text { J.O. Freire }\end{array}$ & $\begin{array}{l}\text { Tratamento de } \\
\text { efluentes e } \\
\text { produção de água } \\
\text { de reuso para fins } \\
\quad \text { agrícolas }\end{array}$ & $\begin{array}{c}\text { http://www2.i } \\
\text { frn.edu.br/ojs } \\
\text { /index.php/H } \\
\text { OLOS/article } \\
\text { /view/9192/p } \\
\text { df }\end{array}$ & $11 / 12 / 2019$ & $\begin{array}{l}\text { Diante dos resultados encontrados, conclui-se que a fertirrigação com } \\
\text { efluente tratado é uma atitude sustentável que mostra eficiência quando } \\
\text { relacionada ao processo mais comum de irrigação, com água potável } \\
\text { ou bruta. Se usado de forma equivocada, pode expor a saúde humana } 0 \\
1234567012345 \text { Concentração de coliformes termotolerantes } \\
\text { (LogNMP/100mL) Tempo (dias) DECAIMENTO BACTERIANO } \\
\text { PARA COLIFORMES TERMOTOLERANTES TORRES ET AL } \\
\text { (2019) HOLOS, Ano 35, v.8, e9192, 2019 14 a riscos, mas é possível } \\
\text { se preservar e respeitar o tempo necessário para manter contato direto }\end{array}$ \\
\hline
\end{tabular}

Fonte: elaborada pelos autores. 


\begin{tabular}{|c|c|c|c|c|c|}
\hline & & & & & $\begin{array}{c}\text { com a planta, dificultando a contaminação após a suspensão da } \\
\text { irrigação. }[\ldots]\end{array}$ \\
\hline 10 & $\begin{array}{c}\text { Cíntia Regina } \\
\text { Fick; Roberta } \\
\text { Giglio; Isabel } \\
\text { Cristina } \\
\text { Machado de } \\
\text { Lara. }\end{array}$ & $\begin{array}{l}\text { O museu como } \\
\text { espaço } \\
\text { interdisciplinar: } \\
\text { projeto de } \\
\text { reutilização da } \\
\text { água desenvolvido } \\
\text { por estudantes do } \\
\text { ensino fundamental }\end{array}$ & $\begin{array}{c}\text { https://reposit } \\
\text { orio.pucrs.br/ } \\
\text { dspace/bitstre } \\
\text { am/10923/11 } \\
\text { 699/2/O_mus } \\
\text { eu_como_esp } \\
\text { aco_interdisc } \\
\text { iplinar_projet } \\
\text { o_de_reutiliz } \\
\text { acao_da_agu } \\
\text { a_desenvolvi } \\
\text { do_por_estud } \\
\text { antes_do_Ens } \\
\text { ino_Fundame } \\
\text { ntal.pdf }\end{array}$ & $13 / 12 / 2016$ & $\begin{array}{l}\text { Por meio da proposta foi possível comprovar que, como afirmam } \\
\text { alguns autores, de fato os museus interativos são espaços de } \\
\text { aprendizagem que contribuem significativamente para construção de } \\
\text { conhecimento uma vez que permitem interação entre visitante e os } \\
\text { experimentos visitados. Dessa forma, as visitações aos museus } \\
\text { interativos instigam a motivação e melhoram o desempenho dos } \\
\text { estudantes. Isso remete o professor à reflexão do quão relevante são as } \\
\text { práticas pedagógicas dinâmicas e motivadoras tanto no espaço de } \\
\text { educação formal, quanto em um espaço não formal como o museu. [...] }\end{array}$ \\
\hline
\end{tabular}


O corpo textual foi analisado por meio da frequência de palavras, que originou a nuvem de palavras (Figura 1) criada na Plataforma online WordArt. Esta ferramenta agrupa e organiza graficamente as palavras-chave evidenciando-as as mais frequentes

Figura 1 - Nuvem de palavras

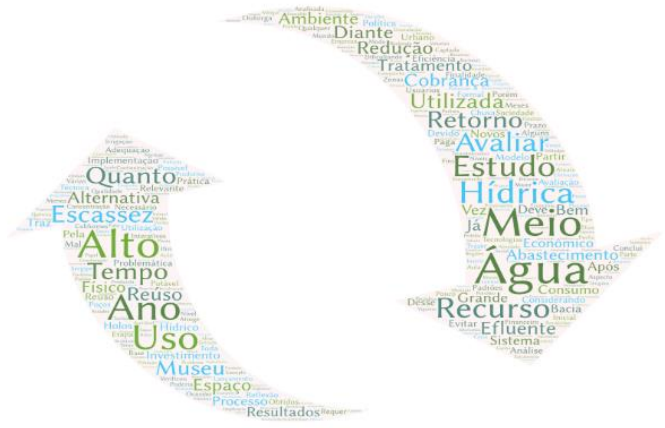

Fonte: elaborada pelos autores.
Por meio da Figura 1, foi possível observar que as palavras em evidência na nuvem pertencem as categorias desenvolvidas a partir da análise de conteúdo de Bardin. Todas as categorias derivam da sua frequência (Tabela 1), que diz respeito ao seu quadro referencial. Em consonância ao objetivo deste trabalho, optou-se por descrever as palavras que apresentaram frequência total no texto e, a partir de seus sentidos nos campos textuais, tinham maior relevância para as representações sociais sobre o reuso da água como uma ferramenta para a gestão de recursos hídricos, como apresentado na Figura 1.

Tabela 1.

Frequência das palavras presentes nos textos publicados nas Plataformas....

\begin{tabular}{|c|c|c|}
\hline PALAVRAS & FREQUÊNCIA & CATEGORIAS \\
\hline Água & 19 & \multirow{3}{*}{$\begin{array}{l}\text { Reuso de águas pluviais para mitigação da } \\
\text { escassez hídrica }\end{array}$} \\
\hline Meio & 5 & \\
\hline Recurso & 5 & \\
\hline Escassez & 4 & \multirow{3}{*}{ Reutilização de efluentes para abastecimento } \\
\hline Hídrica & 4 & \\
\hline Abastecimento & 4 & \\
\hline
\end{tabular}

Fonte: elaborada pelos autores.

\section{DISCUSSÃO}

\section{Reuso de águas pluviais para mitigação} da escassez hídrica

A água da chuva sem dúvida nenhuma é uma das principais fontes hídricas mais puras que se tem no meio ambiente, pois a partir dessa premissa podese estabelecer critérios e processos para o uso e reuso da mesma.

As águas pluviais são a fonte de abastecimento das bacias hidrográficas, porém não há um aproveitamento adequado desse recurso, pois muitas vezes é desperdiçado por não haver um sistema eficiente que possa coletar e destinar boa parte desse volume hídrico dos centros urbanos para essas bacias. Sendo assim, os processos de captação desse recurso se tornam essencial em regiões onde há uma escassez considerável do mesmo, com isso vale salientar que é indispensável haver todo um sistema integrado de reaproveitamento que seja economicamente viável e que traga o mínimo de prejuízos ao meio ambiente.

Cabe principalmente ao poder público e às entidades como a ANA tomarem a iniciativa de planejamento $\mathrm{e}$ elaboração de táticas, técnicas, projetos e 
soluções para que todos os processos de captação, direcionamento, armazenamento, tratamento e distribuição para as atividades diárias da população.

\section{Reutilização de efluentes para abastecimento}

Em áreas industriais é bastante comum a utilização de água "limpa" para fins não nobres, como por exemplo, para o resfriamento das caldeiras e frigoríficos, com isso é gerada um grande volume de efluentes que trazem agentes químicos capazes de danificar o ambiente de despejo.

\section{CONCLUSÃO}

A proposta desse estudo é permitir que esse tema seja mais relevante, por ser algo que é preciso para a sociedade, trazendo consigo o desenvolvimento e a sustentabilidade, a partir da premissa que existem vários locais no país que praticam a racionalização de água, e sendo assim o tema em questão pode ser uma solução sustentável. É certo que a reutilização de águas no país não é tão desenvolvida e não recebe a atenção que deveria receber, entretanto esse tema com a devida atenção dos órgãos responsáveis pode ser o diferencial pela redução da demanda de água e o uso exacerbado da mesma, pois tais medidas do reuso da água iriam favorecer a população reduzindo a escassez em várias regiões, e evitaria a redução extrema do nível de água nos mananciais.

Devemos ter em mente que a água de reuso apresenta uma qualidade inferior à água potável, portanto ela é indicada para casos como geração de energia, refrigeração, lavagem de automóveis,

\section{REFERÊNCIAS}

Com isso, é interessante que haja uma rede de tratamento para que toda essa água, ou pelo menos grande parte dela seja reaproveitada novamente, tanto pela indústria quanto pela população em si.

Portanto, é necessário que haja toda uma infraestrutura, processos e estudos que comprovem cientificamente a qualidade dessa água após a mesma passar por todas as etapas de purificação. Contudo, é primordial a participação da ANA no ato de fiscalizar e oferecer suporte, para que a descontaminação da água seja realizada de forma correta.

irrigação, combate a incêndios e para a limpeza das ruas. Essas tarefas não necessitam de água potável para o seu desenvolvimento e isso faz com que uma maior quantidade de água potável seja direcionada ao abastecimento da população.

Mesmo apresentando muitos benefícios o reuso de água no Brasil ainda é uma prática pouco utilizada e que está no seu estágio inicial, grande parte se deve a falta de aceitamento da população por questões culturais e a falta de uma política governamental que vise fazer o uso adequado dessas águas para um melhor aproveitamento, tanto financeiro quanto ambiental.

O reuso de águas é uma das melhores alternativas para contornar a atual crise hídrica que o Brasil apresenta. Esta reutilização faz com que a quantidade de esgoto que são lançados no meio ambiente diminua, aumenta a quantidade de água potável o que servirá em casos de necessidade, além de promover um uso sustentável dos recursos hídricos.

Duca, T. D., \& Pimentel, J. D. S. (2017).

Gestão E Indicadores De Abastecimento

De Água No Setor Urbano De Lagoa Real 
- Bahia. Geopauta, 1(3), 38.

https://doi.org/10.22481/rg.v1i3.2046

BARBOSA, A. M. D. A., NAVONI, J. A., \& Tavares, J. L. (2019). Caracterização E Análise Do Potencial Da Água Produzida Como Alternativa Para Reúso. Holos, 8, 115.

https://doi.org/10.15628/holos.2019.9200

Morais, N. W. S., \& Santos, A. B. dos. (2019). Análise dos padrões de lançamento de efluentes em corpos hídricos e de reúso de águas residuárias de diversos estados do Brasil. Revista DAE, 67(215), 40-55. https://doi.org/10.4322/dae.2019.004

Silva Chaves, V., Máximo Almeida Albuquerque, T., \& Coêlho Mendonça, L. (2020). Análise da viabilidade econômica, ambiental e social da implantação do sistema de reúso de água em uma indústria de revestimento cerâmico. Revista DAE, 69(228), 6-15.

https://doi.org/10.36659/dae.2021.001

Cristina Mendonça, R., LENNER DE ANDRADE SOARES, K., \& Max Goulart Coelho, L. (2016). Análise da disponibilidade e demanda de água cinza no pavilhão de aulas da Universidade
Federal de Viçosa, Campus Rio ParanaíbaMG. Scientia Cum Industria, 4(2), 98-102. https://doi.org/10.18226/23185279.v4iss2p 98

Becker, E. L. S., Rossato, J., \& Ellwanger, A. (2019). A preservação da água em um objeto de aprendizagem: saberes e possibilidades de ensino. Ensino Em ReVista, 296-319. https://doi.org/10.14393/er-v26n2a2019-1

Pinheiro, L. G., \& Araújo, A. L. C. (2017). Qualidade E Aproveitamento Da Água De Chuva. Holos, 8, 135. https://doi.org/10.15628/holos.2016.3431

Torres, D. M. (2019). Tratamento De Efluentes E Produção De Água De Reúso Para Fins Agrícolas. Holos, 8, 1-15. https://doi.org/10.15628/holos.2019.9192

Developed, R., Elementary, B. Y., \& Students, E. (n.d.). O Museu Como Espaço Interdisciplinar: Projeto De Reutilização Da Água Desenvolvido Por Estudantes Do Ensino Fundamental the Museum As an Interdisciplinary Space: a Project of Water. 